\title{
Automatic data processing and analysis system for monitoring region around a planned nuclear power plant
}

\author{
Jari Kortström, Timo Tiira, and Outi Kaisko \\ Institute of Seismology, Department of Geosciences and Geography, University of Helsinki, Finland \\ Correspondence to: Jari Kortström (jari.kortstrom@helsinki.fi)
}

Received: 22 July 2015 - Revised: 2 March 2016 - Accepted: 2 March 2016 - Published: 10 March 2016

\begin{abstract}
The Institute of Seismology of University of Helsinki is building a new local seismic network, called OBF network, around planned nuclear power plant in Northern Ostrobothnia, Finland. The network will consist of nine new stations and one existing station. The network should be dense enough to provide azimuthal coverage better than $180^{\circ}$ and automatic detection capability down to $M_{\mathrm{L}}-0.1$ within a radius of $25 \mathrm{~km}$ from the site.

The network construction work began in 2012 and the first four stations started operation at the end of May 2013. We applied an automatic seismic signal detection and event location system to a network of 13 stations consisting of the four new stations and the nearest stations of Finnish and Swedish national seismic networks. Between the end of May and December 2013 the network detected 214 events inside the predefined area of $50 \mathrm{~km}$ radius surrounding the planned nuclear power plant site. Of those detections, 120 were identified as spurious events. A total of 74 events were associated with known quarries and mining areas. The average location error, calculated as a difference between the announced location from environment authorities and companies and the automatic location, was $2.9 \mathrm{~km}$. During the same time period eight earthquakes between magnitude range $0.1-1.0 \mathrm{oc}-$ curred within the area. Of these seven could be automatically detected. The results from the phase 1 stations of the OBF network indicates that the planned network can achieve its goals.
\end{abstract}

\section{Introduction}

Pyhäjoki at the eastern coast of the Bay of Bothnia is a potential area for a new nuclear power plant. The area is characterized by low-active intraplate seismicity, with earthquake magnitudes rarely exceeding 4.0. Specific safety guide of International Atomic Energy Agency (IAEA, 2010) states that when a nuclear power plant site is evaluated a network of sensitive seismographs, having a recording capability for microearthquakes, should be installed to acquire more detailed information on potential seismic sources. The operation period of the network should be sufficiently long to obtain a comprehensive earthquake catalogue for seismotectonic interpretation (IAEA, 2010), and the monitoring of natural hazards shall be commenced no later than the start of construction and shall be continued up until decommissioning (IAEA, 2003). The data processing, reporting and network operation are advised to be linked to the national or regional networks. Earthquakes recorded within and near such a network should be carefully analyzed in connection with seismotectonic studies of the near region (IAEA, 2010).

Tiira et al. (2015) outlined a plan for a local seismograph network OBF to be installed around the Pyhäjoki Nuclear Power Plant (PNPP). An optimal configuration of ten seismograph stations was proposed. The ten broad-band 3-C stations will be within $50 \mathrm{~km}$ from the planned power plant. The authors state that the proposed network should be dense enough to fulfill the IAEA (2010) requirements of azimuthal coverage better than $180^{\circ}$ and automatic event detection capability down to $\sim M_{\mathrm{L}}-0.1$ within a radius of $25 \mathrm{~km}$ from the site. The earthquake location accuracy was anticipated to be $1-2 \mathrm{~km}$ for horizontal coordinates within $25 \mathrm{~km}$ distance from the PNPP and the annual number of earthquakes detected was estimated to be $2\left(M_{\mathrm{L}} \geq \sim-0.1\right)$ within $25 \mathrm{~km}$ radius and $5\left(M_{\mathrm{L}} \geq \sim-0.1-\sim 0.1\right)$ within $50 \mathrm{~km}$ radius from the PNPP (Tiira et al., 2015).

Institute of Seismology of University of Helsinki (ISUH) started to build the proposed network in 2012. Building of the OBF network was divided into two phases. Phase 1 included 
four new stations and they started operation at the end of May 2013. The rest of the network started operation in fall 2015. Valtonen et al. (2012) reported the details on site selection, construction and instrumentation of the stations. All the stations were installed on the ground surface. The main obstacles in the site selection were lack of bedrock outcrops in the vicinity of simulated station locations and willing landowners to lease the land. These facts slightly changed the configuration of the realized network compared to the simulated optimal configuration. However, the changes did not impair the azimuthal coverage or event detection capability of the network (Valtonen et al., 2012). Furthermore in a report by Kortström et al. (2012) ISUH defined a seismic monitoring strategy for PNPP site area. Following the IAEA (2010) guidelines, real-time monitoring of the site area is integrated with the automatic detection and location process operated by ISUH. The monitoring strategy is introduced in Sect. 2 .

The objective of this study is to evaluate the detection and location capability of the planned network. We will evaluate whether the realized network meets the requirements set to the simulated network. Moreover, we will investigate whether the four new stations already improve detection capability and location accuracy of PNPP site area compared to national network. In this study we focus on automatic processing of the data collected from the new stations. Automatic analysis results are presented from the network consisting of the four new stations and the existing nearby stations of the national seismic networks of Finland and Sweden.

\section{Seismic monitoring strategy for OBF network area}

Continuous waveform data from OBF network will be transmitted in real-time via internet to ISUH data server, where they will be transferred to the routine data analysis and archival systems. Thereafter, the recordings are processed with automatic software suitable for detecting microearthquakes in an intraplate seismotectonic environment. The main objective of the automated event processing is to distinguish seismic events from the continuous seismograph recordings for further analyses. Basically, the routine breaks up into three sub-tasks: (1) detection of seismic signals from the background noise; (2) identification and association of detected seismic phases; (3) location and identification of seismic events, determination of source depths and magnitudes.

Detector programs are typically based on STA / LTA ratio methods of which many dates back to works of Allen (1978 and 1982) and Withers et al. (1998). Parameters steering the detector program must be fine-tuned as per the events of interest and noise conditions at the stations. For example, prior to STA / LTA detection process the recordings are usually filtered with band-pass filters that are optimized for the frequency content of the target events (teleseismic, regional, or local). Several methods are also available for identification of the detected phases and for their association to single events (e.g. Tong, 1995; Withers et al., 1999; Satriano et al., 2008). The optimal method depends on both the geographical extent of the network and the type and density of stations. The current ISUH system is described in Sect. 3.

The automatic processing of OBF network data starts with the existing ISUH software. Due to differences in monitoring target between ISUH and OBF networks, the processing is separated into two parallel processes. For regional monitoring purposes, data from two sub-stations of OBF network will be included in the automatic event detection and location system of ISUH. This system monitors events above the magnitude threshold of the national network, currently $\sim M_{\mathrm{L}} 0.9$ (Tiira et al., 2015) in the PNPP site area. The inclusion of all the data from the dense OBF network into the sparse regional network data is not meaningful, because it would increase the number of noise detections in the system that is optimized for sparse regional network.

In the second process earthquakes smaller than threshold magnitude of the national network within PNPP area are searched with separate event processing system customized for OBF network. This system will utilize OBF stations and the nearest online stations of the Finnish and Swedish national networks.

\section{Event detection and location system}

As summarized in Sect. 2, automatic processing of the OBF network data is separated into two parallel systems, aimed for regional and local monitoring. Both systems utilize ISUH automatic event processing software but with different processing parameters and network configurations. The system is based on network processing of three-component (3-C) stations. At a single 3-C site the detection is done with basic STA / LTA-detector. The code used is an implementation of Ruud and Husebye (1992), which, in turn, uses "predicted coherence" measure of Roberts et al. (1989). The original Ruud and Husebye (1992) code produced fully automatic single station bulletin. Location of regional events was based on back azimuth and travel time difference of automatically identified $P$ and $S$ phase detections.

In the ISUH automatic processing of single 3-C stations the association and identification of local and regional $P$ and $S$ phases is handled differently. The aim of single station processing is not to produce reliable event bulletins but to build event seeds for network processing. The event seeds are formed as follows: (1) every detection in a detection log is considered as a possible $P$ phase signal. (2) Every detection following the possible $P$ phase within a certain time window in the same detection $\log$ is considered a possible $S$ phase belonging to the same event as the preceding $P$. (3) Event seeds are formed by computing location for all possible $P$ and $S$ pairs using $P$ and $S$ signal onset times and back azimuth estimate. 
As a result single station event detection log contains a large amount of false events intermingled with real event detections. The next step is to associate phases from the rest of the network with all event seeds. This association is done by calculating theoretical $P$ and $S$ arrival times for every station of the network and for every event seed of single station event logs. A pick in single station's detection log is associated with an event seed as $P$ or $S$ phase if its time matches with theoretical arrival time of $P$ or $S$ phase in a given time window. At this point the theoretical arrival times are calculated for all local or regional phases, namely $\mathrm{Pg} / \mathrm{Pb} / \mathrm{Pn}$ and $S g / S b / S n$ phases. $P g$ and $S g$ are direct waves in the upper crust, $P b$ and $S b$ are waves in the lower crust or along the Conrad discontinuity, and $P n$ and $S n$ are waves refracted below the Mohorovicic discontinuity (Willmore, 1979). An event seed is selected for further processing if the number of associated phases exceeds a threshold value.

At this stage multiple solutions may occur for the same event. Two or more solutions are considered originating from the same event if their location and time matches within certain limits. The most stable solution is selected for another phase association round, which is done with stricter association rules. After the second association round, the events are ready for final location, identification and magnitude determination. The 2-step association method allows the application of low detection thresholds at single stations, a necessary condition for detecting very weak seismic signals. A simplified flow chart of the network processing is shown in Fig. 1.

In both single 3-C station and network processing the location of the events are done with HYPOSAT location program (Schweitzer, 2001). HYPOSAT can use versatile data to obtain source location. ISUH system utilizes single arrival times of $P$ or $S$ phases, travel time difference of $P$ and $S$ phases at the same station, and back azimuth observations. The 1-D velocity model used by ISUH to locate of seismic events in the Fennoscandian shield is shown in Table 1. Automatic solutions include origin time, latitude and longitude of the epicenter, focal depth, magnitude, travel-times of signals at each station and error statistics for each of the estimated parameters. The depth of the event is always constrained to zero during the iterations, because accuracy of the automatic arrival times is not good enough for depth estimation. In addition, more than $95 \%$ of the local and regional events in this area are near surface explosions. Fixed depth often helps achieving more stable solutions for the other source parameters as well. For events identified as earthquakes, the source depth is estimated during interactive analysis. That is, the location program is allowed to iterate the depth with carefully picked phase onsets and/or estimate the depth using depth phases.

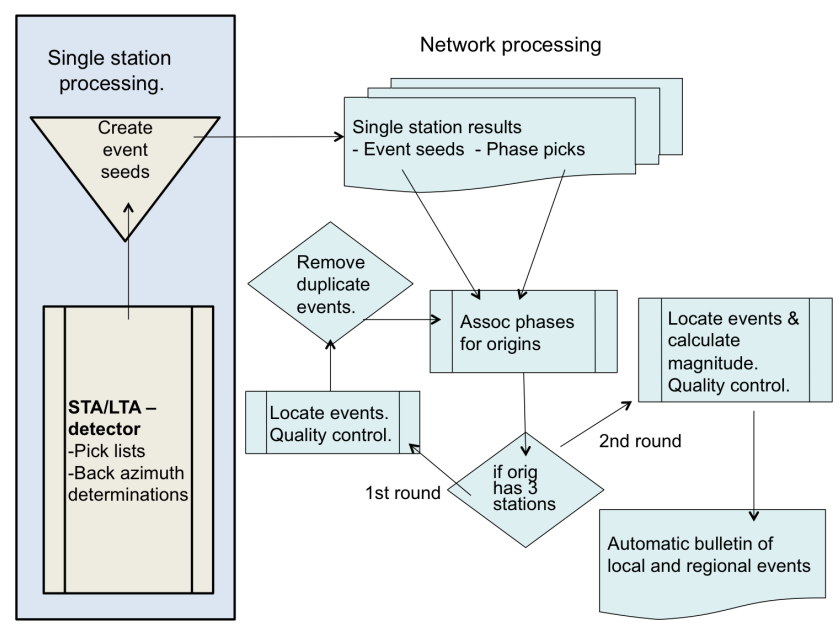

Figure 1. A simplified flow chart of ISUH automatic event processing system.

Table 1. The 1-D velocity model used in the location procedure.

\begin{tabular}{lrr}
\hline $\begin{array}{l}\text { Layer thickness } \\
(\mathrm{km})\end{array}$ & $\begin{array}{r}V p \\
\left(\mathrm{~km} \mathrm{~s}^{-1}\right)\end{array}$ & $\begin{array}{r}V s \\
\left(\mathrm{~km} \mathrm{~s}^{-1}\right)\end{array}$ \\
\hline 15.0 & 6.20 & 3.62 \\
25.0 & 6.70 & 3.84 \\
40.0 & 8.03 & 4.64 \\
& 8.50 & 4.75 \\
\hline
\end{tabular}

\section{Preliminary data processing system for OBF network}

At the end of May 2013 the first four new stations of OBF network started operation. We started the automatic data processing already with the first four stations in order to gain experience of stations' performance as soon as possible. The network used for automatic processing comprised 13 stations: five stations in PNPP area (OBF0, OBF4, OBF6, OBF7 and OUF) and the closest eight stations from the national seismic networks of Finland (OUL, KEF, SUF, TOF, VAF) and Sweden (BURU, KALU, UMAU). The station locations are presented in Fig. 2 together with the predicted minimum magnitude thresholds calculated for this setup. The threshold magnitude map was calculated with same method as in the initial network simulations of Tiira et al. (2015). They derived a relation between event magnitude and maximum distance at which both $P$ and $S$ phase can be automatically detected for that event. Data for the modeling were automatic locations of earthquakes from ISUH database (Tiira et al., 2015). The maps are calculated by forming a $0.1^{\circ} \times 0.1^{\circ}$ grid over the network area. Every grid point is a possible earthquake epicenter from which the distances to the stations are calculated. The distance to the third closest station is then converted to the minimum detectable magnitude at every grid point. This ensures that there should be phase readings from 
Table 2. Detection parameters for Ruud and Husebye (1992) signal detector. First two filter channels are intended for $S$ type signals and latter two for $P$ type signals. STA / LTA detection threshold 1 (Th1) is used together with coherence threshold (Coh) and threshold 2 (Th2) alone. Duration (Dur) is minimum signal duration to accept detection.

\begin{tabular}{rrrrrrrrr}
\hline $\begin{array}{r}\text { Low cut } \\
{[\mathrm{Hz}]}\end{array}$ & $\begin{array}{r}\text { High cut } \\
{[\mathrm{Hz}]}\end{array}$ & $\begin{array}{r}\text { Step length } \\
{[\mathrm{s}]}\end{array}$ & $\begin{array}{r}\text { STA length } \\
{[\mathrm{s}]}\end{array}$ & $\begin{array}{r}\text { LTA length } \\
{[\mathrm{s}]}\end{array}$ & Th1 & Coh & Th2 & $\begin{array}{r}\text { Dur } \\
{[\mathrm{s}]}\end{array}$ \\
\hline 2.0 & 10.0 & 0.08 & 0.16 & 0.64 & 5.1 & 0.9 & 3.0 & 0.8 \\
6.0 & 20.0 & 0.05 & 0.10 & 0.40 & 5.1 & 0.9 & 3.0 & 0.8 \\
5.0 & 20.0 & 0.08 & 0.16 & 0.64 & 3.0 & 0.3 & 3.35 & 0.8 \\
15.0 & 40.0 & 0.05 & 0.10 & 0.40 & 3.0 & 0.3 & 3.55 & 0.8 \\
\hline
\end{tabular}

at least three stations, as required by ISUH automatic location process.

All OBF stations are equipped with similar instruments, that is, Nanometrics Trillium Compact seismometers and EarthData PS-6 digitizers. The sampling rate of the continuous data acquisition is set to 250 sps. For data acquisition we use normal miniPC computers with Linux operating system and SeisComP3 software. We applied the processing system described in Sect. 3 with some modifications: The event seeds were searched only from the five stations within the target area and higher frequency bands for signal detection were applied to the new OBF stations. The main detection parameters for initial signal detection are presented in Table 2.

During the test period of the system, from the end of May to December 2013, we focused mainly to the location accuracy obtained with the system. For that purpose explosions from $50 \mathrm{~km}$ radius from PNPP site were identified and associated to known mines and quarries. Information about blasting sites and times were obtained from environmental authorities and companies carrying out such works. The location error was calculated as a difference of announced location and computed automatic location. Accuracy of automatic event solutions of OBF network was also compared to automatic event solutions obtained by regional network. We utilized explosions from the most active open pit quarry in the area, the Laivakangas gold mine.

\section{Results}

During end of May-December 2013 the automatic analysis system of the OBF network produced 214 event solutions inside the predefined area of $50 \mathrm{~km}$ radius around the PNPP site. Of those solutions 94 were real seismic events and 120 were identified as spurious events, that is, events generated by erroneous phase and/or noise associations. The number of real automatic event detections almost doubled in the area compared to the regional monitoring system, which produced 51 automatic event detections for the same time period.

Location accuracy tests were done to a total of 74 events, which could be identified with known place and time. The events and blasting sites are shown in Fig. 3 and the results in Table 3. The average location error of automatic locations was $2.9 \mathrm{~km}$. An experienced seismic analyst also located the

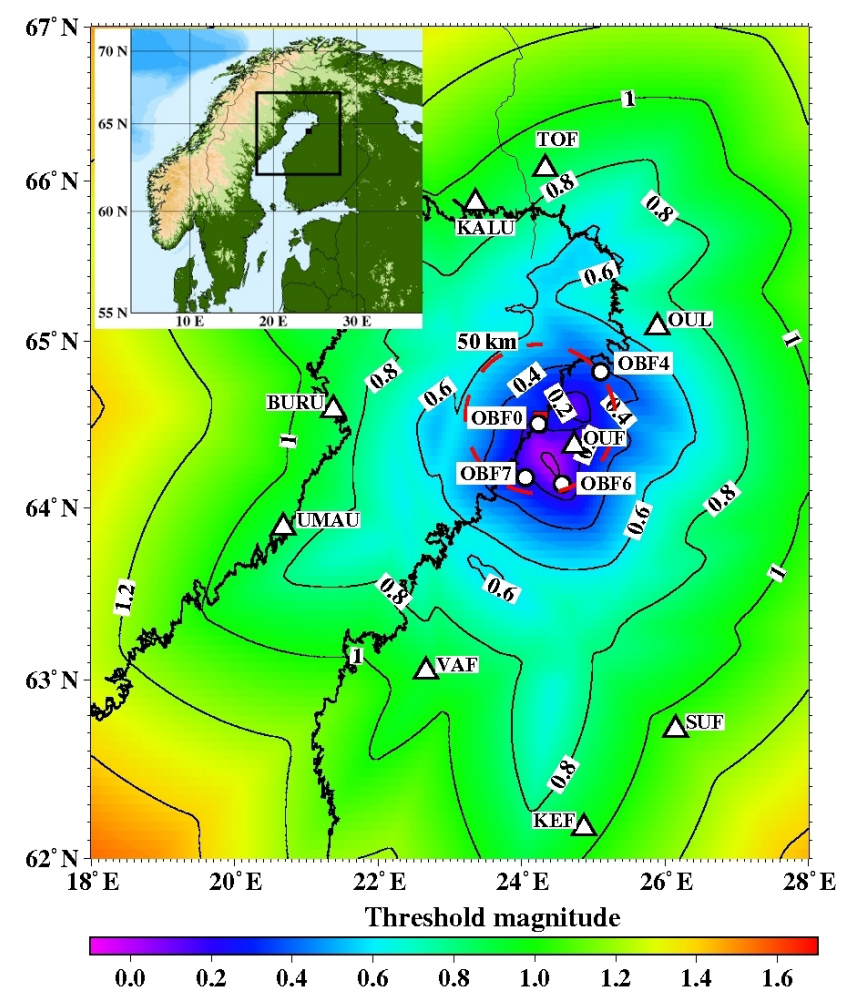

Figure 2. Online seismic stations used by ISUH in the automatic event processing iof PNPP area. A circle denotes a 3-C station of the OBF-network. A triangle denotes a 3-C station of the permanent national networks of Finland and Sweden. Background map is the predicted threshold magnitude calculated for the network shown on the map. The red dashed circumference of $50 \mathrm{~km}$ radius confines the target area of the network. The inset map shows the location of the study area and the PNPP site is marked with a black square.

events interactively. Average location error of these locations for the same events was $1.2 \mathrm{~km}$. In the area between stations OUF, OBF6 and OBF7, which is a near complete part of the network, the average location error was $2.4 \mathrm{~km}$ for automatic solutions and $0.8 \mathrm{~km}$ for manual solutions. Altogether $19 \mathrm{ex}-$ plosions from the Laivakangas gold mine were automatically located with both local and regional systems. The average location errors of OBF network and regional network were 3.3 and $5.4 \mathrm{~km}$, respectively. 
Table 3. Results of location accuracy tests.

\begin{tabular}{lrr}
\hline Location error [km] & Automatic locations & Manual locations \\
\hline 50 km radius from PNPP & 2.9 & 1.2 \\
Area between OBF6, OBF7 \& OUF & 2.4 & 0.8 \\
\hline & OBF network & Regional network \\
\hline Laivakangas gold mine, automatic locations & 3.3 & 5.4 \\
\hline
\end{tabular}

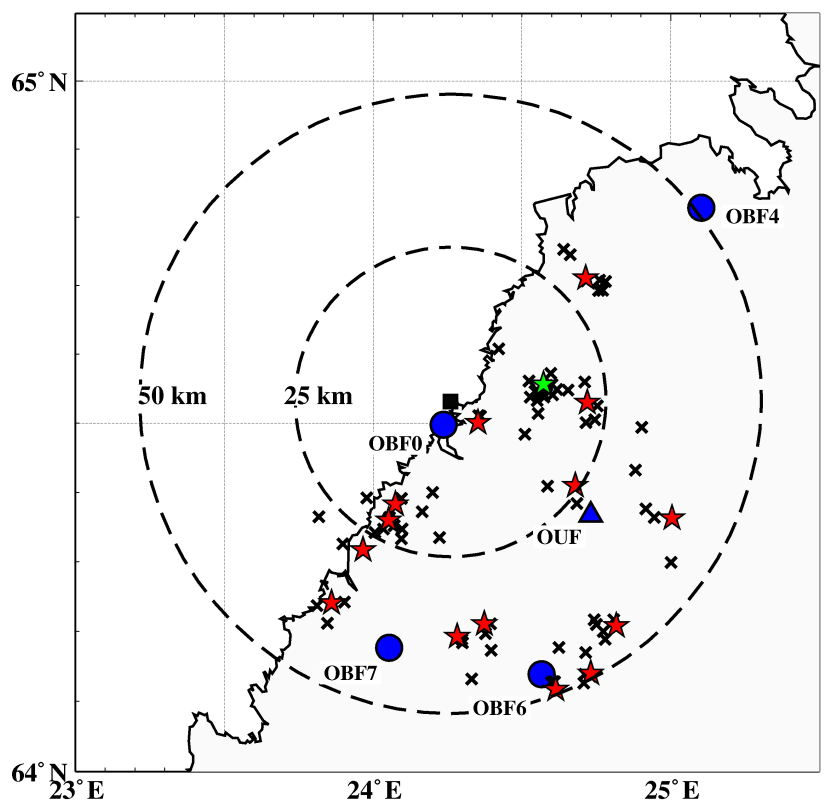

Figure 3. Automatic locations of events from known blasting sites. Blasting sites are marked with red stars except the Laivakangas gold mine, which is marked with green star. Automatic event locations are marked with black crosses. Blue circles are the new seismic stations in the OBF area and blue triangle the pre-existing station OUF. The dashed circles define areas of 25 and $50 \mathrm{~km}$ radii from the PNPP (black square).

After the visual inspection of the automatic analysis results, three of the detected events were identified as earthquakes. The local magnitudes of these events were $0.5,0.8$ and 1.0 calculated using a local magnitude scale by Uski and Tuppurainen (1996). The regional network had also detected the two largest earthquakes. Finally, the seismograms of OBF network were scanned visually to pick weak events missed by the system. As a result five additional earthquakes were found within $50 \mathrm{~km}$ radius of PNPP site. Magnitudes of these earthquakes ranged from 0.1 to 0.4 . Locations of these undetected earthquakes were compared to the predicted detection threshold map of the first stage OBF network, which suggests that the magnitude 0.4 earthquake should have been automatically detected. Figure 5 is shows the recordings of the magnitude 0.4 earthquake with manual phase picks. The automatic processing related to these undetected earthquakes

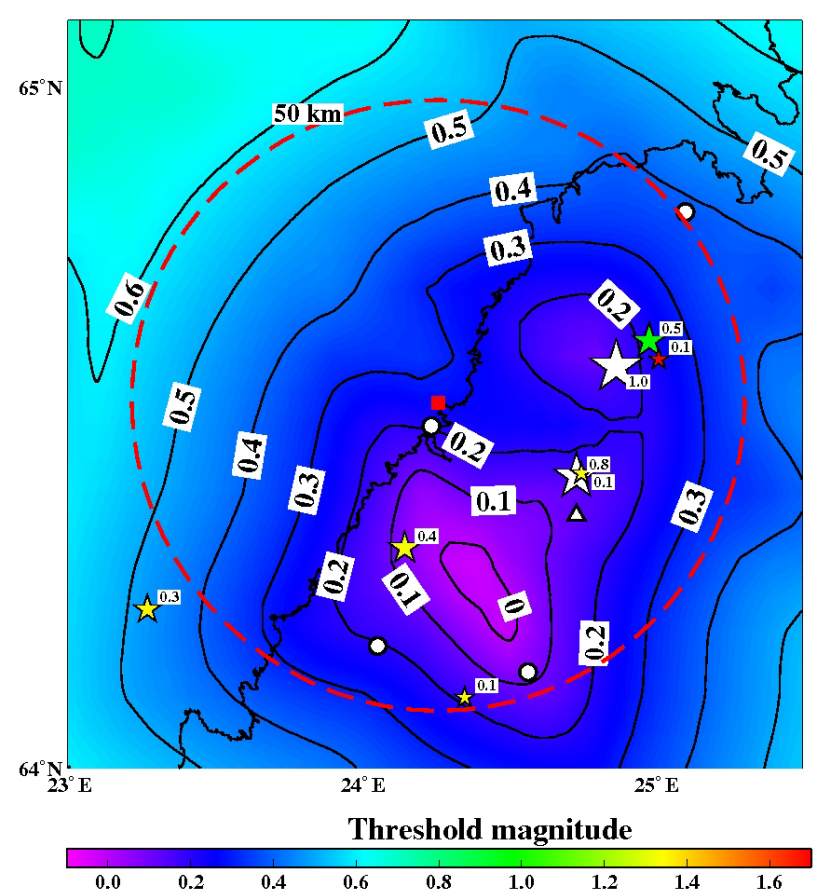

Figure 4. Locations of earthquakes (stars) that occurred at the PNPP area between the end of May and December 2013. Earthquakes marked with white stars were detected automatically by both regional and local OBF networks. Green star denotes earthquake that was detected automatically only by the OBF network. Earthquakes marked with yellow stars were detected by the OBF network after readjustment of detection parameters. Earthquake marked with red star remained undetected. White circles denote the new OBF stations and white triangle is the pre-existing station OUF at the area. Dashed red circle defines the area of $50 \mathrm{~km}$ radius from the PNPP site (red square). Background shows the predicted magnitude threshold map for the network used in local automatic system (cf. Fig. 2).

was examined closely. As a result adjustments were made to STA and LTA window lengths of single station processing and phase association rules of network processing. Recordings of earthquakes were reprocessed with new settings and now four more earthquakes were automatically detected. As a result the automatic system detected smaller earthquakes than magnitude threshold map predicts (Fig. 4). Details of the 
Table 4. Source parameters for earthquakes recorded by OBF in 2013. Origin time, latitude and longitude in WGS-84 coordinate system, depth $\left(F=\right.$ fixed during the location process) and local magnitude $M_{\mathrm{L}}$.

\begin{tabular}{rrrrrcr}
\hline & Date & Time, UTC & Lat $\left({ }^{\circ} \mathrm{N}\right)$ & Lon $\left({ }^{\circ} \mathrm{E}\right)$ & Depth $(\mathrm{km})$ & $M_{\mathrm{L}}$ \\
\hline 1 & 26.05 .2013 & $00: 23: 02.5$ & 64.585 & 24.867 & 24.5 & 1.0 \\
2 & 16.07 .2013 & $02: 07: 49.4$ & 64.428 & 24.748 & 24.0 & 0.1 \\
3 & 27.07 .2013 & $12: 52: 45.8$ & 64.230 & 23.269 & 10.7 & 0.3 \\
4 & 08.11 .2013 & $03: 24: 29.7$ & 64.102 & 24.350 & 6.8 & 0.1 \\
5 & 07.12 .2013 & $20: 44: 13.1$ & 64.623 & 24.979 & 24.7 & 0.5 \\
6 & 07.12 .2013 & $20: 44: 19.5$ & 64.596 & 25.012 & $20 F$ & 0.1 \\
7 & 16.12 .2013 & $17: 31: 49.8$ & 64.424 & 24.731 & 8.9 & 0.8 \\
8 & 17.12 .2013 & $09: 43: 03.0$ & 64.319 & 24.146 & 25.7 & 0.4 \\
\hline
\end{tabular}

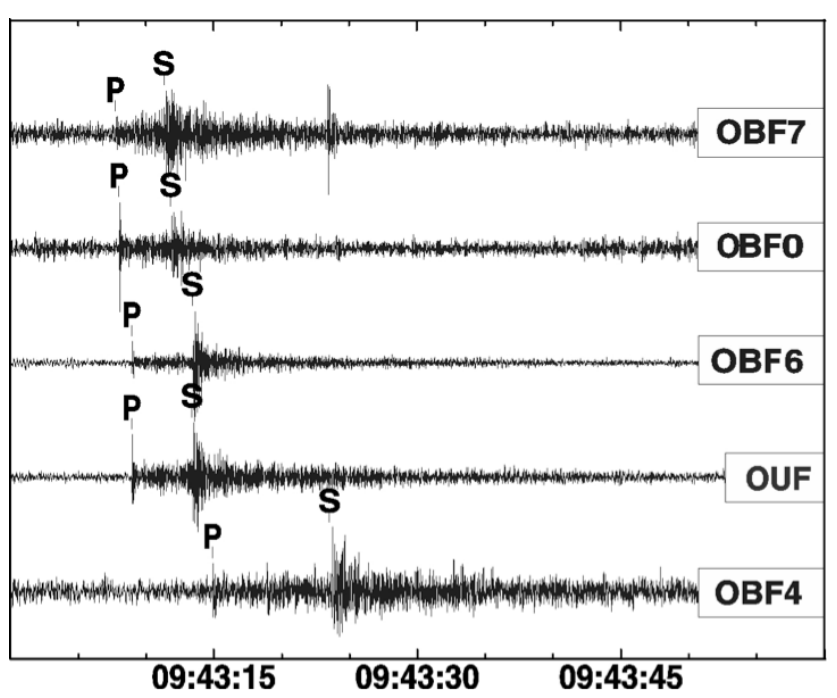

Figure 5. Vertical recordings of the $M_{\mathrm{L}} 0.4$ earthquake in Kalajoki 17 December 2013 at the OBF-stations. The recordings are presented with increasing station to epicenter distance. The arrival times of first $P$ and $S$ arrivals are marked. Recordings are filtered with a $2-30 \mathrm{~Hz}$ band pass filter.

all earthquakes recorded by the OBF network in the PNPP area are given in Table 4.

Background noise of the new sites was also studied. Short test measurements had been already made during site surveys, which suggested that the noise levels are comparable to other locations in Finland (Valtonen et al., 2012; Korja et al., 2011). The analysis of the new sites confirmed that the overall background noise is at the same good level as in the most of the Finnish stations. Analyses were made using pqlxsoftware (McNamara and Boaz, 2005). Figure 6a-e shows the probability density functions of the four new stations and pre-existing station OUF at the area. Differences between OUF and new OBF stations at low frequency (long period) part of the spectra are due to the different seismometers used in these stations. OUF is equipped with Streckeisen STS-2 seismometer while the Nanometrics Trillium Compact seismometers of the OBF stations are less sensitive at low fre- quencies. There are also variations in high frequency part of the noise spectra between the stations. The new OBF stations have higher sampling rate $(250 \mathrm{sps})$ compared to station the OUF (100 sps). Thus, noise spectra of new OBF stations contain more site-specific variations from short distances.

\section{Discussion}

IAEA 3.30 (2010) guidelines state that when a nuclear power plant site is evaluated a network of sensitive seismographs having a recording capability for micro-earthquakes should be installed to acquire more detailed information on potential seismic sources. In areas with high seismicity the active faults are seen clearly when large number of earthquakes are located evenly inside of error margins of potential fault lines. In such areas low detection threshold is not a necessity. In areas of low seismicity both low detection threshold and good location accuracy are substantial when trying to map active faults using earthquake locations. When location accuracy is good, even single events can be associated with certain faults, whereas location errors measured in many kilometers make the single observations useless in seismotectonic interpretations (Korja et al., 2011).

Location accuracy gained with phase 1 stations of the OBF network is comparable to earlier studies (e.g. Bondár et al., 2004; Korja et al., 2011; Uski et al., 2011) with similar conditions. Our results show that the overall location accuracy of manual locations is already at the level predicted by the network simulations (Tiira et al., 2015). Furthermore, the location accuracy results indicate that the accuracy of both automatic and manual locations is best at the near complete part of the network, that is, in between of stations OUF, OBF6 and OBF7. It is a known fact that the location accuracy can be improved with accurate local velocity model and sufficient number of evenly spaced seismic stations near the source (e.g. Bondár et al., 2004; Uski et al., 2011). If the source is outside the network, in other words the maximum azimuthal gap of event location is greater than $180^{\circ}$, the location accuracy decreases rapidly (Tiira et. al., 2015). In addition location accuracy can also be improved by applying relative location methods (e.g. Waldhauser and Ellsworth, 2000; Fehler et 
(a)

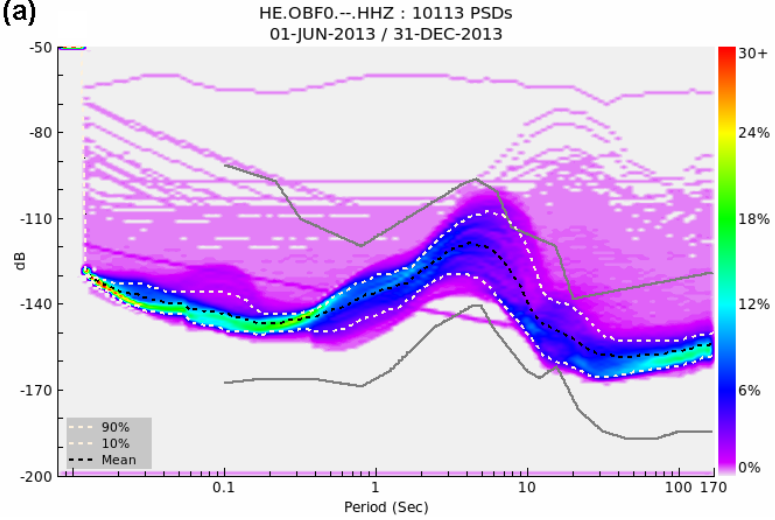

(c)

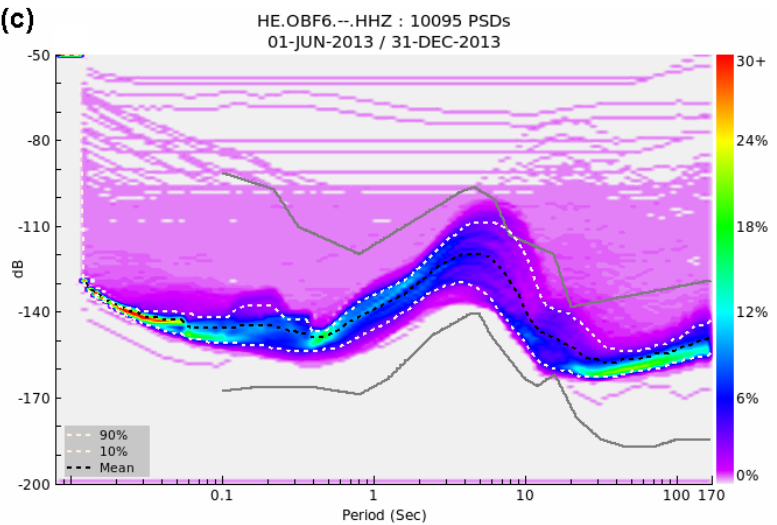

(b)

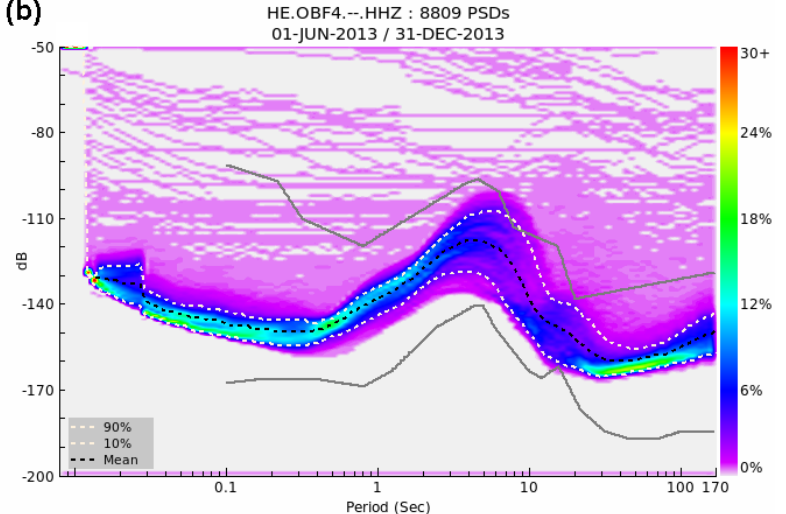

(d)

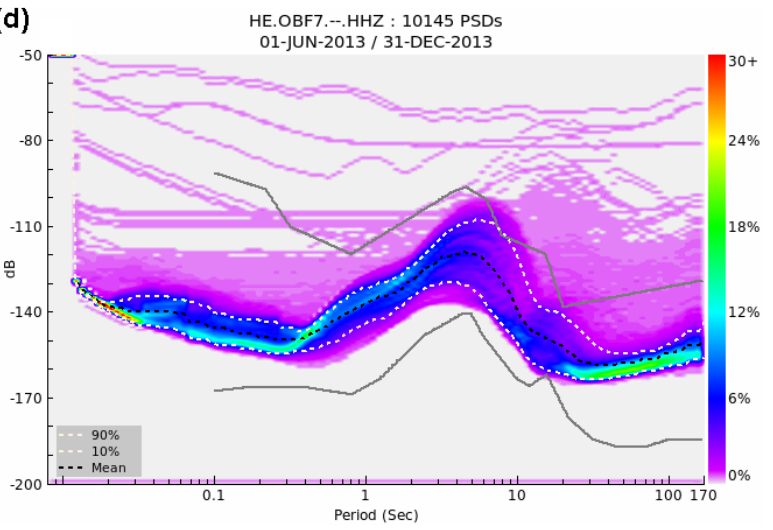

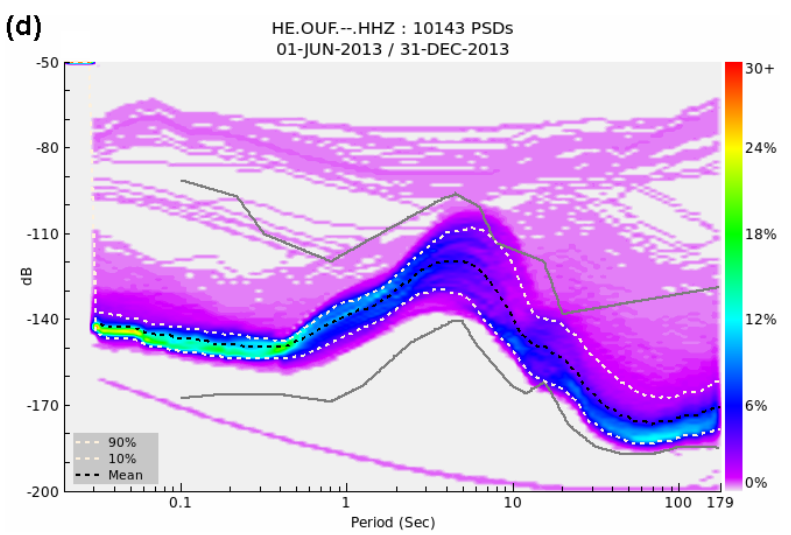

Figure 6. A spectral density function at station OBF0 (a), OBF4 (b), OBF6 (c), OBF7 (d) and OUF (e). The background noise at the station is seen as regularly observed energy levels (blue, green, yellow and red). The more scarce energy levels (pink and violet) are associated with sudden disturbances such as signals of seismic events. The grey lines denote the global average of low and high noise level models (Peterson, 1993).

al., 2000; Castellanos and Van der Baan, 2013). In summary, our results with phase 1 stations of the OBF network implies that the complete OBF network can achieve a good location accuracy within $50 \mathrm{~km}$ radius of PNPP site, at least at the in-land part of the network.

The new stations helped to find six small $\left(M_{\mathrm{L}}<0.8\right)$ earthquakes, which would probably have remained undetected using national network only. The number of $M_{\mathrm{L}}>0$ earthquakes found in 2013 is in fact greater than what was pre- dicted by Tiira et al. (2015). Most of the small earthquakes would still have remained undetected without visual scanning of the waveforms. The automatic analysis system applied to the phase 1 stations of OBF network performed quite poorly. The false alarm rate was relatively high and the system missed one earthquake it should have detected according to predicted detection capability. This was somewhat expected as the applied system was not properly tuned for local distances. Nevertheless, preliminary results look promising 
for the ultimate goal of the network. Our experience from the regional processing of Finnish networks and contributing stations from neighboring networks has proven that event association rejects spurious events effectively when number of stations increases. Thus, we expect the false alarm rate to decrease when the network is complete and number of stations doubled from five to ten. At the same time we expect that number of automatically detected earthquakes will increase significantly.

The automatic data processing system used in Sweden and Iceland, called SIL (Bödvarsson and Lund, 2003), has similarities with our automatic processing software. The software uses STA / LTA detector to initial phase picking and the processing is divided in single station and multi station parts. The SIL system was originally developed to monitor automatically microearthquake activity around Icelandic volcanoes where it has shown the capability of automatic evaluation of more than 1500 earthquakes per day (Bödvarsson and Lund, 2003). In Sweden the SIL system is applied to the data of the Swedish National Seismic Network (SNSN) that consists of more than 60 stations with station spacing of about $100 \mathrm{~km}$. The network is sufficiently sensitive to record all earthquakes down to a magnitude 0.5 within the network (Bödvarsson, 2011).

Lindblom (2011) studied microearthquakes along Pärvie fault of Northern Sweden. She set up a temporary network to improve detection capability and location accuracy of the SNSN. The network comprised seven temporary stations and a subset of suitable SNSN stations in the study area. She used the SIL system to process the data and as a result, like in our study, the number of spurious events was large. Also the explanation of false alarms is similar to our study: "the network's standard automatic event detection and location procedures were not optimal for the temporary station data set" (Lindblom, 2011). Nevertheless, Lindblom (2011) could increase the number of automatically detected earthquakes with temporary stations compared to the SNSN. Moreover, by using time-domain cross-correlation detector the number of initial automatic detections was doubled (Lindblom, 2011). Waveform correlation is a well-established technique to identify close-lying events, which produce very similar waveforms at same stations if the source mechanism is similar. Waveform correlation is especially powerful in detecting signals that fall below the detection capability of energy based detectors as shown in previous studies like Gibbons et al. (2007) in Norway and Withers et al. (1999) in New Mexico.

The INGV National Seismic Network in Italy has undergone large improvements since the beginning of the new millennium, as described by Amato and Mele (2008). The improvements included tripling of on-line stations from less than 100 to more than 200 and having three component broad-band sensors for the majority of the stations. Compared to the year 2000, the INGV network doubled the number of earthquake detections in year 2006. Also the magni- tude completeness of the whole network region improved from 1.7 in year 2006 to 2.4 in year 2000. Quality of automatic locations was found to be good, meaning less than $10 \mathrm{~km}$ difference to manual location, inside the network with the improved network (Amato and Mele, 2008). These findings support our findings that with sufficient number of wellsituated stations the OBF network can achieve its goals.

The development of automatic processing system of the OBF network will continue in coming years. The current system needs refining of parameters in every stage of processing and new methods should be introduced. In the future usage of cross-correlation detector could increase the number of detected small earthquakes and the location accuracy can be further improved with relative location methods. These methods will be applied after sufficient amount of ground truth data from earthquakes and chemical explosions has been recorded with all stations of the completed network.

Acknowledgements. Seismic stations operated by the Institute of Seismology, University of Helsinki, the Sodankylä Geophysical Observatory, University of Oulu, and the Uppsala University have provided online waveform data for this study. The maps in Figs. 2-4 were prepared with the Generic Mapping Tools (GMT; Wessel and Smith, 1991, 1998).

Edited by: D. Pesaresi

Reviewed by: three anonymous referees

\section{References}

Allen, R.: Automatic earthquake recognition and timing from single traces, B. Seismol. Soc. Am., 68, 1521-1532, 1978.

Allen, R.: Automatic phase pickers: their present use and future prospects, B. Seismol. Soc. Am., 72, S225-S242, 1982.

Amato, A. and Mele, F. M.: Performance of the INGV National Seismic Network from 1997 to 2007, Ann. Geophys.-Italy, 51, 2-3, 2008.

Bödvarsson, R.: Swedish National Seismic Network (SNSN) - A short report on recorded earthquakes during the third quarter of the year 2011. Report P-10-33, Swedish Nuclear Fuel and Waste Management Co, Stockholm, Sweden, 15 pp., 2011.

Bödvarsson, R. and Lund, B.: The SIL seismological data acquisition system - as operated in Iceland and in Sweden, in: Methods and Applications of Signal Processing in Seismic Network Operations, edited by: Takanami, T. and Kitagawa, G., Springer Verlag, Berlin, Germany, number 98 in Lecture Notes in Earth Sciences, 2003.

Bondár, I., Myers, S. C., Engdahl, E .R., and Bergman, E. A.: Epicentre accuracy based on seismic network criteria, Geophys. J. Int., 156, 483-496, 2004.

Castellanos, F. and Van der Baan, M.: Microseismic event locations using the Double-Difference algorithm, CSEG Recorder, 38, 2636, 2013.

Fehler, M., Phillips, W. S., House, L., Jones, R. H., Aster, R., and Rowe, C.: Improved Relative Locations of Clustered Earth- 
quakes Using Constrained Multiple Event Location, B. Seismol. Soc. Am., 90, 775-780, 2000.

Gibbons, S., Sorensen, M., Harris, D., and Ringdal, F.: The detection and location of low magnitude earthquakes in northern Norway using multichannel waveform correlation at regional distances, Phys. Earth Planet. In., 160, 285-309, doi:10.1016/j.pepi.2006.11.008, 2007.

International Atomic Energy Agency (IAEA): Site Evaluation for Nuclear Installations. Safety Requirements Series No. NS-R-3, Vienna, Austria, 28 pp., 2003.

International Atomic Energy Agency (IAEA): Seismic hazards in site evaluation for nuclear installations. Specific safety guide SSG-9, Vienna, Austria, 60 pp., 2010.

Korja, A., Kortström, J., Lindblom, P., Mäntyniemi, P., Uski, M., and Valtonen, O.: Seismisten aineistojen kerääminen ja tulkinta Pyhäjoen alueelta, Report M210E2010, Geological Survey of Finland, 35 pp., 2011.

Kortström, J., Uski, M., Tiira, T., and Korja, A.: Data processing and analysis system for the Pyhäjoki seismic network, Report T-86, Institute of Seismology, University of Helsinki, Helsinki, Finland, 15 pp., 2012.

Lindblom, E.: Microearthquake Study of End-glacial Faults in Northern Sweden, Licentiate thesis, Uppsala Universitet, Uppsala, Sweden, available at: http://uu.diva-portal.org/smash/get/ diva2:456600/FULLTEXT01.pdf (last access: 9 March 2016), 2011.

McNamara, D. E. and Boaz, R. I.: Seismic Noise Analysis System, Power Spectral Density Probability Density Function: Stand-Alone Software Package, United States Geological Survey Open File Report, NO. 2005-1438, 30 pp., 2005.

Peterson, J.: Observations and modelling of background seismic noise, Open-file report 93-322, US Geological Survey, Albuquerque, New Mexico, USA, 1993.

Roberts, R. G., Christoffersson, A., and Cassidy, F.: Real-time event detection, phase identification and source location estimation using single station three-component seismic data, Geophys. J. Int., 97, 471-480, 1989.

Ruud, B. O. and Husebye, E. S.: A new three component detector and automatic single-station bulletin production, B. Seismol. Soc. Am., 82, 221-237, 1992.
Satriano, C., Lomax, A., and Zollo, A.: Real-time evolutionary earthquake location for seismic early warning, B. Seismol. Soc. Am., 98, 1482-1494, 2008.

Schweitzer, J.: HYPOSAT - An Enhanced Routine to Locate Seismic Events, Pure Appl. Geophys., 158, 277-289, 2001.

Tiira, T., Uski, M., Kortström, J., Kaisko, O., and Korja, A.: Local seismic network for monitoring of a potential nuclear power plant area, J. Seismol., 20, 397-417, 2015.

Tong, C.: Characterization of seismic phases - an automatic analyser for seismograms, Geophys. J. Int., 123, 937-947, 1995.

Uski, M. and Tuppurainen, A.: A new local magnitude scale for Finnish seismic network, Tectonophysics, 261, 23-37, 1996.

Uski, M., Tiira, T., Grad, M., and Yliniemi, J.: Crustal seismic structure and depth distribution of earthquakes in the Archean Kuusamo region, Fennoscandian Shield, J. Geodyn., 53, 61-80, 2011.

Valtonen, O., Lindblom, P., Komminaho, K., Kortström, J., Keskinen, J. Smedberg I., and Korja, A.: Suunnitelma Pyhäjoen seismisestä paikallisverkosta. Report T-85, Institute of Seismology, University of Helsinki, Helsinki, Finland, 19 pp., 2012.

Waldhauser, F. and Ellsworth, W.: A double-difference earthquake location algorithm: Method and application to the northern Hayward fault, B. Seismol. Soc. Am. 90, 1353-1368, 2000. Wessel, P. and Smith, W. H. F.: Free software helps map and display data, EOS Trans. AGU, 72, 441-448, 1991.

Wessel, P. and Smith, W. H. F.: New, improved version of Generic Mapping Tools released, Eos Trans. AGU, 79, p. 579, 1998.

Willmore, P. L.: Manual of Seismological Observatory Practice. World Data Center A for Solid Earth Geophysics, Report SE-20, September 1979, Boulder, CO, USA, 165 pp., 1979.

Withers, M., Aster, R., Young, C., Beiriger, J., Harris, M., Moore, S. and Trujillo, J.: A comparison of select trigger algorithms for automated global seismic phase and event detection, B. Seismol. Soc. Am., 88, 95-106, 1998.

Withers, M., Aster, R., and Young, C.: An automated local and regional seismic event detection and location system using waveform correlation. B. Seismol. Soc. Am., 89, 657-669, 1999. 